\title{
GÊNESE SOCIAL DO EDITOR E AS NOVAS CONDIÇÕES DE PRODUÇÃO DO LIVRO
}

\author{
Antonio Paulino de Sousa*
}

\begin{abstract}
Este artigo relaciona o problema da edição tradicional com as novas tendências no campo editorial e busca estabelecer as condições sociais de produção do livro. O editor é um mediador entre o autor e o seu público. Esta relação dialética entre editor e autor é importante para a compreensão do produto final que é o livro. O editor exerce uma função crítica determinante no processo de construção, circulação e atribuição de novos significados. Por essa razão fala-se em termos de escrita editorial, cuja atividade está sendo questionada pelas novas estratégias de leitura na Web. O problema essencial é a filtragem na Web. O gesto editorial continua sendo indispensável para a legitimação e validação científica dos discursos.

Palavras-chave: Poder. Editor. Campo Editorial. Enunciação Editorial, Web.
\end{abstract}

\section{INTRODUÇÃO}

Este artigo aborda um problema que não se resolve facilmente: as condições sociais de produção do livro e o poder do editor. É complexa a relação entre o autor e o editor. A sociologia da cultura contribui na elaboração deste problema ao relacionar a edição tradicional com as tendências contemporâneas no campo editorial. Esta problemática é relativa ao papel histórico e social do editor que hoje é questionado pela edição na Web. Elaborar o problema em termos editorias é pensar a partir de um ponto de vista particular que relaciona as novas formas de escrita com a nova função social do editor. O livro é uma expressão do advento e da expansão da tipografia que cumpre integralmente os requisitos como objeto de estudo, configurando um dos nós preferenciais de interpretação da razão moderna (Chartier, 1988).

Historicamente o campo da edição se desenvolveu com o investimento de indiví-

* Doutor em Sociologia e em Ciências Econômicas e Sociais. Professor da Universidade Federal do Maranhão. Centro de Ciências Sociais, Departamento de Educação II. Av dos portugueses, s/n. Bacanga. Cep: 65.110.000. São Luís - Maranhão - Brasil. antonio.paulino@terra.com.br duos que detinham um forte capital escolar e um capital de relações no campo universitário. E o crescente desenvolvimento da cultura fez emergir a necessidade de instrumentos de legitimação e de regulação da qualidade dos produtos culturais que são ofertados aos consumidores destes bens. Daí por que as normas e regras de produção e distribuição são asseguradas pelos editores. Esta vigilância epistemológica tem por objetivo validar os discursos científicos ao estabelecer os critérios que permitem reconhecer aqueles que estão de acordo com o que é exigido em um determinado campo do conhecimento. O editor funciona como um filtro que seleciona os manuscritos de acordo com a sua política editorial e em consonância com o que é exigido pela lógica de cada campo científico. Ele seleciona e diz o que deve e o que não deve ser publicado. No entanto, isso não nos autoriza a afirmar que o editor é o "legislador" que define, isoladamente, a publicação de um manuscrito. Ele está inserido em uma rede de relações de produção e reprodução da cultura legítima na qual os conselhos editorias (e demais intelectuais e colaboradores) exercem um papel determinan- 
te na orientação das políticas editorias. É nessa perspectiva que o conceito de campo editorial é pertinente para pensar o conjunto dos agentes envolvidos no ato da edição do livro. O conceito de campo exclui a possibilidade de se pensar que o editor tem o poder exclusivo de criação do gosto literário e da constituição do próprio campo literário.

O editor é o mediador central do campo editorial. Ele estabelece a relação entre o autor e o seu público, que são os leitores. O que caracteriza o editor é a sua prática de leitura que se distingue das demais leituras. Por isso o editor é definido como aquele que tem o poder de assegurar, não somente a publicação, mas, também, a circulação do livro. Assim, é o editor que faz existir socialmente o autor, caso este preencha os requisitos elaborados pela política editorial, em função das condições econômicas e culturais. Neste sentido, a cada momento histórico, os produtos culturais estão inscritos nas instituições e nas estruturas mentais. A acumulação legítima do autor e do editor consiste em fazer existir um produto cultural e um nome que seja conhecido e reconhecido no interior de cada campo cultural. É desta forma que os editores são condição necessária para a constituição de uma esfera pública literária e para a constituição de um espaço crítico. As L2 regras de circulação são essenciais para a proసิ dução e reprodução das condições sociais de existência do autor e do editor. A prática desฐิ te último participa da estruturação da obra e ¿ orienta a leitura. Assim, a mediação impressa กิ diz respeito à enunciação editorial e se desen$\vec{\sim}$ volve mais ainda com a escrita editorial.

○ O editor não é apenas um mediador en$\therefore$ tre o autor e o público. Ao transformar o maจ nuscrito em livro, ele atribui um novo signifi-

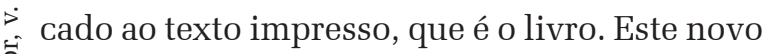
significado não está instituído, apenas, pela tipografia, mas, também, pelas possíveis correções que são feitas nos manuscritos. Desse modo, o papel do editor tem sido questionado, na contemporaneidade, pela interação instituída entre a tela e a escrita. Esta nova textu- alidade e os diferentes modos de produção e interpretação conferem uma nova estrutura de significado. Isto implica que novas estratégias de leitura das informações devem considerar a imagem e o texto. Mas a internet, por exemplo, não suprime as dificuldades cognitivas da entrada na escrita. É por isto que se deve analisar as formas de produção e as condições sociais de produção da escrita. Assim, as relações entre autor e editor tendem a se modificar mais ainda com as novas tecnologias.

Neste sentido, há uma evolução na estrutura social do campo editorial e o problema central é a filtragem na Web. Pois toda cultura coloca em prática determinados filtros, que se distinguem da censura. Estas práticas de filtragem têm uma longa história e exercem um poder simbólico sobre a produção dos bens culturais. A autoridade que filtra é um conselheiro. A supressão do filtro corresponde à eliminação do papel crítico do editor e, portanto, da enunciação editorial. O gesto editorial é indispensável no processo de produção da legitimação e validação de um discurso, de um livro. Na sociedade informacional, o que se discute é a relação entre o tempo e o espaço.

A função editorial se inscreve no âmbito da racionalidade moderna porque ela exerce um poder de crítica e de legitimação dos bens culturais. O grande problema na Web é a identificação das instâncias editoriais. Mas a função editorial não se limita ao conteúdo do que é publicado. O papel do editor implica uma capacidade crítica para atribuir uma forma e um novo significado ao texto, que envolve os profissionais da indústria cultural. Enfim, o editor tem uma função importante na orientação do leitor. Assim, não é possível dissociar autor, editor e leitor, uma vez que eles fazem parte de um sistema de produção e reprodução cultural. Elaborar o problema em termos editoriais corresponde a pensar a partir de um ponto de vista particular que relaciona as novas formas de escrita com a nova função social do editor, que tem o papel determinante, não apenas de selecionar, mas, também, de fazer circu- 
lar os livros e, assim, dar uma existência social ao autor a ponto de investir, pessoalmente, na defesa do livro publicado. Este modo de intervenção estrutural do editor está vinculado à intermediação das novas tecnologias e seus diversos componentes, que configuram as práticas sociais e a emergência de um novo tipo de mercado de livros on-line.

\section{GÊNESE E PODER DO EDITOR}

Os problemas relativos ao editor e à edição são pouco estudados. As grandes revistas científicas francesas, Revue historique, Revue d'histoire moderne et contemporaine, Annales ESC trataram do livro e, mais raramente, da edição. A Histoire de l'édition française (1982-1986) é uma das primeiras obras sobre a questão, seguida por uma outra obra escrita na Bélgica: Histoire du livre et de l'imprimerie em Bélgique (Mollier; Sorel, 1999, p. 39). Claude Pichois escreveu um artigo pioneiro na revista Annales em 1959 sobre a edição e a sua tese fez emergir a importância do livro e da edição. A história da edição adquire a sua autonomia no seio da comunidade científica (Pichois, 1959).

O que me orienta a estudar este objeto é propriamente o fato de que o papel histórico e social do editor é hoje questionado pela edição na Web. Esta nova tendência é um problema no campo editorial. A relação entre autor e editor é determinante para a filtragem e a qualidade do que deve ser publicado. É o editor que cria as condições de possibilidade de um mercado do livro, que oferece condições ideais para a circulação do livro impresso e cria, também, condições para a existência social do autor.

Não há dúvida de que a literatura, antes de ser o encontro entre o livro e o leitor, é, primeiramente, um conjunto de manuscritos considerados como tal pelos editores. Ora, o que os editores retêm é uma quantidade ínfima de toda a produção cultural bruta de um país e de um determinado período histórico. Com isso, observa-se com clareza que a seleção editorial tem uma história. Na concepção de Chatier (apud Medeiros, 2010, p. 255) a

[...] atividade editorial que seleciona ou ordena os textos, controla as operações pelas quais os textos se tornam livros e assegura a sua distribuição aos compradores é declaradamente o processo fundamental em que se consuma a interligação entre a história das técnicas e a história da produção, a sociologia do comércio livreiro e a sociologia da leitura, o estudo físico dos livros e o estudo cultural dos textos.

Em 1730 surge a figura do editor. O termo era uma referência ao livreiro letrado cuja característica era a habilidade na escolha de livros de qualidade. Ele discernia o escritor que poderia agradar ao público e envolvia-se politicamente no ato da publicação de determinados tipos de pensamentos. O editor passa a exercer um grande poder no processo de formação dos gostos, no momento em que importaram para o campo de produção do livro um sistema de disposições que era o efeito de sua relação com o campo da pesquisa e do ensino.

A legitimidade da coleção de Félix Alcan, Bibliothèque de philosophie contemporaine, era forte no campo da filosofia e pode-se dizer que ele detinha o monopólio da edição filosófica francesa. Mas esse monopólio não é total devido ao surgimento de novos editores como Flammarion, por exemplo (Fabiani, 1988). O controle que o editor exercia sobre os autores engendrava uma prática discursiva em conformidade com os procedimentos de exposição e análise das questões, obedecendo ao estilo e à orientação universitária (Fabiani, 1988, p. 109). Foi o crescente desenvolvimento do setor da cultura na França que fez emergir a necessidade de instrumentos de legitimação e de avaliação. Este problema é bem ilustrado pela interrogação de Sartre: Qu'est-ce que lalittérature? (O que é a literatura?). A resposta de Sartre é parcialmente sociológica, afirma Fabiani (1993, p. 150-151).É através do livro que os membros de uma sociedade podem se ver e fazer uma avaliação da sua situação, diz Sartre (1948, p. 196).

O problema central é saber quem tem legitimidade para falar em nome da filosofia ou 
da literatura, por exemplo. Aí a preocupação é, não apenas de ordem científica, mas, também, ideológica e comercial (Fabiani, 1988, p. 111). Para Fabiani, os filósofos só adquirem seu verdadeiro sentido quando são estudados a partir do campo de produção filosófica e, também, em referência às normas em função das quais suas obras são produzidas e difundidas. Estas normas e códigos são as regras de produção e distribuição que são administradas pelos editores em geral. A vigilância epistemológica que visa validar o discurso científico é bem analisada por Michel Foucault (2009) na Ordem do discurso e, também, por Ernest Cassirer (1991) na Logique des sciences de la culture.

Um editor não se pronuncia sobre o valor de um manuscrito, mas sobre a publicidade, sobre a possibilidade de inscrever o texto no catálogo da sua editora e difundir para o grande público. Neste sentido, há um investimento intelectual e político do editor, como bem nos faz entender Jerôme Lindon, gerente da editora Editions Minuit, "Eu publico livros nos quais eu penso poder me investir a fim de defender o livro e impô-lo junto ao público" (Fouché; Simonin, 1999, p. 108). Ao descrever a relação entre editor e um manuscrito, Sartre compara o livro com um editorial de um cotidiano. Para um contemporâneo do autor, ـ submerso na mesma subjetividade histórica, సे a leitura significa participar dos riscos do empreendimento. O editor deve fazer aparecer as สี่ qualidades raras do livro (Sartre, 1948, p. 43). - Mas os mecanismos de produção dos livros e ¿ 2010, p. 249), não é possível confinar os livros

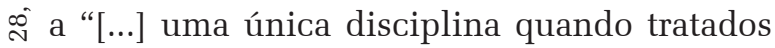
$\vec{\Delta}$ como objeto de estudo. Nem a história, nem a literatura, nem a economia, nem a sociologia, nem a bibliografia conseguem fazer justiça a todos os aspectos da vida de um livro"

Robert Gallimard nota que o autor cujo livro é publicado e os autores cujos livros não são publicados escrevem, finalmente, a mesma coisa, mas não escrevem da mesma forma (Fouché; Simonin, 1999, p. 108). A forma na qual se anuncia a objetividade literária é o que permite a emergência mais profunda do real, a que está bem escondida, porque a realidade é um véu que permite ao autor e ao leitor dissimular a realidade. A estrutura da escrita é dissimulada pelo trabalho que dá forma à própria escrita (Bourdieu, 1992, p. 61 e 57). A análise de Sartre se inscreve nesta mesma orientação, pois, para ele, o indivíduo não se torna escritor simplesmente por ter escolhido dizer certas coisas, mas por dizer certas coisas de uma determinada forma. É o estilo que faz o valor da prosa. Mas ele deve passar despercebido, diz Sartre. A forma, cada um inventa a sua e, depois, faz-se o julgamento (Sartre, 1948, p. 75-76).

O editor é definido como aquele que tem o poder de assegurar a publicação e a circulação dos bens culturais. É ele quem faz com que um manuscrito e um autor possam ter uma existência social reconhecida. Neste caso, é necessário compreender o processo de seleção que distingue o que deve e o que não deve ser publicado no interior de uma produção cultural. Mas a decisão de aceitar ou recusar a publicação é definida após uma confrontação dos julgamentos e das discussões do Comitê Científico, o qual dispõe de um poder de avaliação e de decisão sobre a publicação. Neste ponto, nota-se prontamente que é preciso levar em conta os dispositivos institucionais (de uma editora) que fazem uma triagem entre o publicável e o não publicável a partir dos manuscritos que são propostos pelos autores. Mais precisamente, é necessário apreender as relações objetivas entre os diferentes agentes que têm influência e que contribuem no processo de decisão do que deve ser publicado (Bourdieu, 1999, p. 3). O escritor é sempre associado a seus críticos. Sartre nos deixou uma grande contribuição para o entendimento da relação dialética entre leitor, escritor e os críticos. O seu livro O que é literatura? é uma exposição sistemática do campo literário e de suas regras. Bourdieu, nas Regras da Arte, avança mais ain- 
da na análise sociológica da relação dialética entre o autor, editor e seus críticos. Para ele, Manet instaura a pluralidade dos pontos de vista (Bourdieu, 1992, p. 191).

A disjunção entre a ação política e o julgamento científico caracteriza as grandes editoras e revistas científicas e há razões para tal. A exemplo disso, o editorial da Revue française de sociologie (2009) retém duas razões principais. A primeira é definida pela competência e independência. A tendência é que os pesquisadores realizem suas pesquisas sobre objetos que poucos estudam e, assim, são poucos pesquisadores que têm competência para julgar determinados trabalhos. A ausência dessa competência abre portas para uma multiplicidade de falsos valores, mas a independência significa que a lógica do julgamento deve se exercer de forma autônoma. A segunda diz respeito à distinção entre ação política e ação científica. A prática da avaliação científica se situa em um meio profissional marcado pela concorrência e pela cooperação. É o poder colegial dos pesquisadores competentes, concorrentes e independentes que fundamenta a legitimidade do julgamento científico de um editor. Essa vigilância epistemológica é válida tanto para livros quanto para os periódicos científicos. Afirmar que o poder de avaliação é do domínio dos pares é tomar posição sobre a construção do saber e a constituição de novas disciplinas. É necessário reconhecer, como diz Sartre (1948, p. 125), que há qualidades em um livro que emergem unicamente com o julgamento dos críticos.

A função da crítica do editor consiste em analisar a estrutura de um manuscrito, a sua arquitetura e o jogo de relações internas. A obra não pode ser compreendida sem esta relação entre editor e autor. A relação institucional que se estabelece é entre uma editora e um escritor e é por isto que o intelectual é indiscutivelmente coletivo. É preciso poucos anos para que um livro, segundo Sartre (1948, p. 12 e 40), se torne um fato social passível de ser interrogado como uma instituição e, nes- se caso, o editor não se interessa diretamente pelo autor. O editor vê no autor uma produção espontânea de uma consciência coletiva, algo como uma instituição.

\section{Neste caso,}

[...] o nome de autor serve para caracterizar um certo modo de ser do discurso: para um discurso, ter um nome de autor, o fato de se poder dizer 'isto foi escrito por fulano' ou 'tal indivíduo é o autor', indica que esse discurso não é um discurso cotidiano, indiferente, um discurso flutuante e passageiro, imediatamente consumível, mas que se trata de um discurso que deve ser recebido de certa maneira e que deve, numa determinada cultura, receber um certo estatuto (Foucault, 1992, p. 45).

Mas o autor carrega consigo o nome da editora que o faz existir socialmente. A produção cultural dos autores não se limita apenas aos livros, mas eles criam a possibilidade e a regra de formação de outros textos. Os autores criam condições e possibilidades infinitas de novos discursos. "A obra constitui uma estrutura significativa fundada na existência de uma estrutura mental coerente e elaborada por um sujeito coletivo" (Foucault, 1992, p.76). O que define o autor é a sua capacidade de alterar, de reorientar o campo epistemológico e estabelecer um novo paradigma. "O autor é finalmente um renovador do campo epistemológico" (Foucault, 1992, p. 86-87).

Nota-se que a determinação da singularidade permanece fragmentária e incerta sem a investigação da posição que cada editora ocupa no campo editorial. E esta posição depende da distribuição dos recursos raros tais como o capital econômico, simbólico, técnico, entre outros. É pela estrutura de sua posição que a editora orienta a tomada de decisões e suas estratégias em matéria de publicação dos manuscritos. A maior mudança que se pode observar, dentro de uma política editorial de diferentes editoras, pode também ser relacionada às mudanças na posição que elas ocupam no campo editorial (Bourdieu, 1999, p. 4). O procedimento de oferta de manuscritos para os editores é o produto de uma seleção regulari- 
zada pela lógica do campo e pela posição da editora na estrutura do campo editorial.

Os autores, ao enviarem os seus manuscritos, se orientam em função da representação que eles fazem dos diferentes editores e de suas relações com as escolas de pensamento. E cada editora elabora a sua política editorial em função das condições econômicas e culturais e, também, do espaço dos possíveis, como diz Bourdieu (2012). Assim, a cada momento da história, os produtos culturais estão inscritos objetivamente nas instituições (nas editoras, no caso dos livros) e subjetivamente nas estruturas mentais. A exigência elementar do editor consiste em não confiar inteiramente nos relatórios de leitura. É deste jogo entre autor, editor e conselho editorial que emerge o livro. Este, por sua vez, é definido como um objeto ambíguo no sentido de que ele tem um valor econômico e cultural. "A arte da criação solitária foge das determinações conjunturais" (Bourdieu, 1999, p. 5).

A publicação envolve uma grande diversidade de espaços, de técnicas, de máquinas e de indivíduos.

No antigo regime tipográfico, as intervenções propriamente editoriais se realizam não na ortografia, na grafia ou na pontuação do texto, mas nas escolhas feitas em razão dos públicos visados e que co-

$\stackrel{2}{2}$ mandam as decisões quanto ao formato, ao papel,
a
(Ch caracteres, à presença ou não de ilustrações
(Chartier, 2002, p. 68).

A regra editorial é rígida. Os editores desempenham um papel essencial de mediação cultural inventando as fórmulas que permitem relacionar o repertório textual com a capacidade produtiva. É a multiplicação da produção impressa que é vista como um perigo nos primórdios da invenção do editor. Para dominar esse possível excesso tornam-se necessários instrumentos que permitem selecionar, classificar, hierarquizar. Estas orientações cabem a múltiplos atores sociais, mas os editores, por suas escolhas, desempenham um papel essencial nessa domesticação da abundância. Os editores, como agentes intermediários,
[...] ocupam os lugares de inscrição da cultura impressa que arvoram a articulação social entre o núcleo e a franja, ocorrendo uma alternância entre separação e fluidez de fronteiras. É nessa elasticidades em que o domínio cultural se firma que o investigador percebe e constata o papel da mediação, cartografando os eixos de consenso e de conflito através dos artefatos culturalmente produzidos (Medeiros, 2010, p. 243).

O maior sentimento de qualidade de um texto está ligado à coerência. É a estrutura, interna e externa, do conjunto do texto que deve ser analisada pelo editor. Ele pode fazer revisão do manuscrito para adaptá-lo ao leitor ideal. O termo revisão designa o resultado da atividade scripteur/réviseur e os diferentes procedimentos que são tomados dentro do processo de revisão. A revisão é inerente ao processo da escrita e se divide em releitura (reading) do primeiro manuscrito e a correção (editing). As estratégias de correção são objetos de um aprendizado. Se o editor critica o escritor é porque ele sabe escrever. No século XVII, saber ler já é saber escrever bem. Os autores do século XVII têm uma função bem definida porque eles se dirigem a um público esclarecido, rigorosamente ativo, exercendo sobre ele um controle permanente (Sartre, 1948, p. 134 e 137).

Os autores mobilizam a atividade de revisão como uma atividade autônoma e introduzem uma distinção entre revisão externa (revising), que diz respeito à superfície do texto, e a revisão interna, que diz respeito ao conteúdo semântico. A releitura (re-reading) é, então, concebida como uma avaliação da adequação do texto produzido ao objetivo que foi fixado pelo scripteur no momento do processo de planificação. A correção (editing) consiste na aplicação de regras de produção destinadas a resolver os problemas encontrados pelo scripteur que deve adequar suas intenções comunicativas e suas realizações linguísticas. A revisão é entendida, aqui, como acréscimo, supressão, substituição, mudanças e distribuição (Marin; Legros, 2010, p. 115). Os editores têm consciência de que o sucesso de um livro 
depende do local de publicação. Isto contribui para a compreensão da importância do editor como mediador entre o autor e o leitor. A acumulação legítima do autor e do editor consiste em fazer um nome conhecido e reconhecido. É uma luta pela distinção e pelo reconhecimento.

Os editores são a condição necessária para a constituição de uma esfera pública literária e para a utilização crítica da razão. A “[...] edição submete a circulação das obras a coerções e a finalidades que não são idênticas àquelas que governaram a escrita. Essas são duas exigências, a tensão não se resolve facilmente." (Chartier, 2002, p. 76). A crítica da razão torna-se uma crítica da cultura cuja pesquisa quer compreender e demonstrar como todo conteúdo cultural repousa sobre um princípio geral e supõe um ato original do espírito (Cassirer, 1972, p. 20). Este ato original é do autor, mas, também, da leitura seletiva do editor, que institui uma forma, um estilo e um modo particular de produzir bens culturais. Estabelece-se uma relação dialética entre autor e editor.

Podemos dizer que o campo editorial é o lugar de circulação do discurso legítimo, da regularidade, da regra e da nominação. Nesta perspectiva, a editora é caracterizada pelo fato de ser o lugar do poder universalmente reconhecido. Este poder reconhecido da editora e do editor é baseado em um consenso social que delega a uma instância que é encarregada de definir o que deve ser lido pelo público e, portanto, o que é bom para o público. O editor detém o monopólio dos meios de produção e de acesso aos bens culturais. Na base da relação entre autor e editor devemos distinguir dois estados do capital: o professor de geografia, por exemplo, é detentor de um capital cultural e existe o detentor de um capital que confere poder a esse capital, trata-se do editor de livros de geografia. $\mathrm{O}$ editor tem uma metacapital e pode decidir se o detentor de um capital simples, o professor de geografia, poderá ou não publicar o seu manuscrito (Bourdieu, 2012, p. 312).

\section{MERCADO E EDIÇÃO}

A lógica do campo editorial é determinada pelas interações no interior do campo. A estrutura do campo editorial determina o tamanho e a estrutura das unidades que são responsáveis pela decisão e define, igualmente, o peso relativo das diferentes formas de avaliação que levam a priorizar o literário em oposição ao comercial, a privilegiar a arte ou o dinheiro. Os autores estabelecem, raramente, a relação entre suas obras e a questão econômica que está no cerne da atividade humana e, portanto, se por um lado ele escreve, por outro ele recebe dinheiro (Sartre, 1948, p. 9). O livro faz, então, emergir um novo mercado. Como todo mercado, este também é marcado pela concorrência. É por esta razão que o editor Hetzel, para lutar contra a dominação, fez uma intervenção política no sentido de garantir a proteção dos autores e editores através dos direitos autorais (Pichois, 1959, p. 528 e 533). É desta forma que se instaura um regime de propriedade para os livros e a relação jurídica entre autores e editores, sobretudo no que diz respeito aos direitos de reprodução da obra. Isto acontece no final do século XVIII e no início do século XIX (Foucault, 1992, p. 47-48).

No que diz respeito ao mercado, o essencial é que as produções comerciais se impõem cada vez mais aos produtos culturais. Esta lógica está presente no campo da edição. A maioria dos editores se orienta a partir da lógica comercial. É impossível não observar que o lucro é a negação da cultura, pois esta supõe investimentos cujos retornos são incertos e, muitas vezes, póstumos (Bourdieu, 2001, p. 79). O que está em jogo é a lógica da produção cultural que não é orientada para fins exclusivamente comerciais em oposição às que estão orientadas para este fim. Isto significa que a cultura está ameaçada pelas condições sociais e econômicas dentro das quais ela pode ser desenvolvida contra a lógica do lucro. É contra essa lógica que os artistas plásticos lutaram pelo direito à assinatura, ou seja, pelo direito 
de ser tratado como autor (Bourdieu, 2001, p. 81). É necessário encorajar a defesa da arte em relação ao econômico.

No Brasil, depois de 1820, Benjamin Louis era proprietário da maior estrutura de edição do Rio de Janeiro. Era o verdadeiro arquétipo do editor brasileiro moderno e ele ilustra, no mundo, o dinamismo da edição francesa no século XIX. Foi ele que decidiu remunerar os escritores lusófonos (Mollier, 1999, p. 31). Mas ele não é o único personagem até porque a história editorial brasileira se confunde com a construção da nação, o que demonstra a importância dos impressos na vida política nacional, conforme a análise de Eliana de Freitas e Jean Mollier (2006). Este setor da economia era dominado pelo editor, que está no centro das decisões editoriais. No campo das forças produtivas em concorrência pelo monopólio do mercado de produção de livros, ele avalia a matéria-prima e entrega às gráficas, para que o manuscrito se transforme em livro. A circulação é um elemento central no processo de produção e de reprodução das condições sociais de produção. Este é um papel do editor. O editor integra esse elemento ao desenvolver uma estratégia de publicidade, por isso a lógica da circulação dos bens culturais não está, necessariamente, à disposição dos autores, que não 12 podem sobreviver com o seu trabalho solitá亏े rio, e sua obra deve integrar um sistema de difusão que esteja em consonância com suas สี่ orientações culturais e intelectuais. O encontro do autor com o grande público depende das ก possibilidades ofertadas pelas editoras, que as$\vec{\sim}$ seguram uma divulgação dos livros junto ao $\curvearrowright$ público interessado em determinado tipo de \& produtos culturais. Nesta perspectiva, o exem๙ plo do mercado do livro no Brasil é pertinente.

Em 1999, o mercado brasileiro do livro ocupava o oitavo lugar na produção mundial. Para Gustavo Sorá (1999, p. 90), esta progressão consagra a transformação dos editores em profissionais do livro e as editoras em verdadeiras empresas de informações. A editora José Olympio, do Rio de Janeiro, ocupava uma posição semelhante à da editora Gallimard e a editora Fundo de Cultura Econômica no México. Estas editoras têm o poder de consagrar os autores e as obras que entrarão no panthéon literário nacional. Foi assim que nasceram, Graciliano Ramos, José Lins do Rego, Gilberto Freire e outros. José Olympio monopoliza a publicação de livros que representam a cultura nacional legítima. Até 1950, ter um livro publicado nesta editora era uma legitimação literária (Sorá, 1999, p. 90 e 93, 96). Os editores têm consciência de que o sucesso de um livro depende do local de publicação.

$\mathrm{O}$ ajustamento entre o autor e o editor e, em seguida, entre o livro e seu público é o resultado de uma série de escolhas que fazem investir em uma imagem de marca do editor e do espaço que ele ocupa no mercado. É em função dessa imagem que os autores escolhem o editor. E os leitores fazem intervir na escolha dos autores a imagem que eles têm do editor (Bourdieu, 1992, p. 235). Isto contribui no processo de compreensão da importância do editor como mediador entre o autor e o leitor. O editor tem um poder de consagração dos produtores e dos produtos culturais. O campo de produção cultural é um local de lutas que visa delimitar a população dos que são escritores e que possuem o direito de participar da luta pela definição do que vem a ser um escritor. A luta pela classificação visa estabelecer, assim, as fronteiras (entre as disciplinas e entre os modos de produção) e a hierarquia dos objetos culturais. A definição das fronteiras corresponde ao estabelecimento da ordem e da defesa do campo (Bourdieu, 1992, p. 313). O setor da livraria é um espaço público onde acontecem os debates característicos de uma esfera pública literária (Habermas, 1985, p. 44-45).

A análise do processo de produção, de legitimação e de recepção das obras constitui um terreno privilegiado para enfretamentos teóricos e metodológicos no interior da sociologia e, também, sobre suas fronteiras. A arte pode ser o suporte de relações originais entre a sociologia e a economia (Menger, 1989). 
Haward é um exemplo desses estudos de obras culturais (Becker, 1985). Assim, o livro de Pierre Bourdieu (1992), As regras da arte, constitui uma tentativa para colocar em prática a lógica que governa a produção dos escritores e das instituições literárias.

O grande problema é relacionar a estrutura da obra com a estrutura da sociedade na qual ela é produzida, independentemente do número e do tipo de mediação pelo qual se chega a estabelecer esta mediação. Nas pesquisas sobre os estudos das formas simbólicas, há uma tendência para a exclusão das preocupações sociológicas. A sociologia da arte não pode se isolar da arte e dos modos sociais de sua produção. É a partir do estudo da produção literária que Bourdieu (1966) apresentou as primeiras formulações do conceito de campo. O campo literário é um sistema de relações, como todos os outros campos, entre os agentes. É isso que explica o fato de que se privilegia mais a sociologia da produção em detrimento da sociologia da recepção (Fabiani, 1993, p. 157). A questão da intertextualidade, Bourdieu (1992, p. 280) a define como a ação das obras sobre as outras obras. Mas essa ação só se exerce através dos autores, de suas estratégias e de seus interesses no interior de um campo.

"A reorganização do mundo do escrito em forma digital é uma preliminar para que possa ser organizado o acesso pago por linha e ser protegido o direito moral e econômico do autor" (Compagnon apud Chartier, 2002, p. 37). Trata-se de uma aliança conflituosa e necessária entre editores e autores, e isto implica, certamente, uma transformação profunda do mundo social e das formas de produção da escrita, assim como na emergência de um novo mercado da edição.

\section{GESTO EDITORAL}

Partindo da noção de recepção editorial, Brigitte Ouvry-Vial engloba os conceitos de escrita e de enunciação editorial em uma noção mais ampla que é o gesto editorial. O processo de produção do livro e a diversidade material dos elementos que o constituem são analisados de forma brilhante por Gerard Genette (1987). No seu livro Seuils, ele propõe uma tipologia e definição do texto na sua complexidade de objeto multiforme e tentaculaire. As análises sobre o autor e a função do editor demonstram que a responsabilidade e a escolha são, primeiramente, do autor e supõem que o discurso editorial, em geral, é subordinado às necessidades do comércio e aos usos estabelecidos. A decisão de publicar é o resultado de um consenso. Genette (1987, p. 68-69) sugere, implicitamente, uma reflexão sobre as maneiras de editar. Estas maneiras são diversas e próprias às pessoas em particular e isto se constitui em efeitos do ato de editar. Enfim, do gesto editorial. O que se percebe é que há uma intencionalidade editorial e, portanto, o livro nunca se apresenta em estado puro, ele é sempre acompanhado de elementos de produção, a partir dos quais pode ser apresentado, recebido e consumido pelo leitor.

O processo de produção, no entanto, separa, nitidamente, o manuscrito e o livro publicado. É uma verdadeira metamorfose. O respeito ao texto e às intenções do autor é a base da produção editorial, mas este processo depende, também, da percepção e da interpretação editorial que são feitas sobre os textos e as intenções do autor. O editor representa, perante o leitor, as condições de possibilidade de recepção do livro, sem, contudo, esquecer a liberdade do leitor, objeto bem explorado por Sartre (1948). O que se nota, então, é a intencionalidade crítica do editor, cujo objetivo específico é oferecer ao leitor uma determinada representação do livro que deve ser ofertado ao consumidor.

Um exemplo clássico é o poder que um Editor como Gallimard exerceu sobre a publicação da obra de Sartre: La nausée. A partir do momento em que o manuscrito foi aceito para a publicação, Brice Pariain assume a responsabilidade de conduzir o processo de publicação. Ele começa pedindo o corte e a eliminação de diver- 
sas passagens, o que foi aceito por Sartre. O título da obra era Melancolia e foi julgado inadequado. É Gallimard que encontra o título adequado: La nauseé. O editor busca um parentesco da obra de Sartre com as figuras de excelência literária como Kafka, que começava a se impor, e uma outra figura é Céline. O jovem Sartre é intencionalmente associado a estes dois autores (Boschetti, 1985, p. 61-62). A publicação da obra é a confluência de um discurso que se constrói entre o autor e seus críticos. Há um ajustamento da obra de Sartre com as intenções do editor. Nota-se, então, que o valor de uma obra é decidido pelo julgamento dos pares e qualquer autor se sente na obrigação de se conformar com a imagem que é feita pelos editores, os críticos e os outros autores (Boschetti, 1985, p. 62). Na sua interpretação, Gallimard, reconhece o caráter intelectual da obra e, no ato da publicação, quer deixar transparecer que La Nausée é uma combinação de Kafka, Husserl e Céline. Neste mesmo sentido, o livro de Jacques Bouveresse (2003, p. 49-50), L'avenir d'une illusion foi aceito pelo editor, mas o título foi recusado e substituído por Le philosophe chez les autophages.

Convém não esquecer que o editor pode publicar e fazer com que uma obra seja imediatamente esquecida. É o caso do livro de Mary Douglas, How Institutions Think, que foi traเ duzido para o francês e publicado pela éditions సं Usher em 1989 com o título: Ainsi pensent les institutions. O livro não foi bem divulgado e, สี além disso, o editor faliu. Dez anos depois, este ivro é traduzido e publicado pela Editora La Découverte com o título: Comment pensent les $\vec{N}$ Institutions (1999), com um prefácio de George Balandier. Desse modo, a autora é introduzida a na França e passa a existir socialmente neste N país, assim como a sua contribuição à socio$\overrightarrow{~ l o g i a ~ d a s ~ i n s t i t u i c ̧ o ̃ e s . ~ O r a, ~ a ~ r e l a c ̧ a ̃ o ~ d e s t a s ~}$ questões nos faz pensar que o editor institui o capital cultural do autor e seu próprio capital simbólico pela magia do coletivo (Bourdieu, 1998, p. 78-79). Os editores são instituídos como grupo e como realidade social e, ao mesmo tempo, constata-se que há diferenças e conflitos no interior do campo. Por instituírem valores, geram uma certa arbitrariedade que é desconhecida como tal pelas fronteiras do campo jurídico. Os valores existem no estado institucionalizado e se reproduzem pela crença coletiva no papel social das editoras.

Trata-se, portanto, de um ato de codificação da obra, pois o editor faz, então, referência a leis específicas do campo literário. O efeito desta invenção pode nos fazer pensar sobre a multiplicidade de funções exercidas pelo gesto editorial, que é uma atividade crítica por definição. Foi esse processo de produção que construiu e consagrou a representação de um autor como Sartre, mas não se deve esquecer que a publicação implica, também, uma relação entre o indivíduo, a sociedade e a história (Boschetti, 1985, p. 67-75). Também Sartre, na condição de editor da revista Critique, implanta uma política editorial que não está em conformidade com a demanda do campo. Esta revista só é lida e apreciada por um público restrito e esta não conformidade se percebe na estrutura do capital dos seus produtores. (Boschetti, 1985, p. 205 e 221).

Sartre teve que ajustar o seu produto aos gostos do mercado, e, por desfrutar de uma posição privilegiada, podia aceitar as fragilidades do seu modelo. Ele estava no centro de um grupo de "neo-agrégés" e entre os seus amigos, leitores competentes e exigentes, que indicam, exatamente, o gosto e as preferências dos seus pares (editores e leitores) de onde depende o reconhecimento (Boschetti, 1985, p. 46). O editor codificou o livro de forma a adaptá-lo às exigências do texto e às práticas de leitura. A intervenção editorial visa oferecer um mínimo de clareza ao texto e o máximo de criação de um terceiro sentido. Mas, para que esta combinação se torne realidade, o editor exige correções nos manuscritos.

Uma reflexão crítica sobre a atividade do editor visa a uma sociologia da leitura e da produção cultural. Isto deve nos levar a estabelecer relações entre escrever, ler e editar. E são estas relações que fazem da edição uma resposta às práticas sociais de leitura e às necessidades 
que emergem dessas práticas sociais. Desde o momento em que se considera o livro como um médium, o que está em jogo é a reconstituição da sua trajetória social e sua história de produção, que está relacionada às escolhas materiais, intelectuais, técnicas e estéticas que são colocadas em prática no processo de transmissão do texto (Ouvry-Vial, 2007, p. 71).

Editar consiste em propor uma leitura de uma obra escrita ou visual por intermédio de um ordenamento conceitual e formal (papel ou tela) que condiciona o sentido e a interpretação da escrita. Logo, o editor contribui em livro que ele não assina diretamente. Considerando as técnicas materiais e intelectuais de transmissão, podemos dizer que estas estão relacionadas a uma determinada política editorial e, independentemente do valor educativo, cultural, social ou literário de uma política editorial, o fato é que o editor é o intérprete das ideias do seu tempo. O editor joga com o papel de leitor e extrapola, a partir de sua própria reação de leitor, antecipando a reação do público, mas o suporte redefine o gosto das obras e as formas de interpretá-las. O gesto editorial deve ser pensado na sua prática e sua finalidade. $\mathrm{O}$ acento deve ser colocado no princípio de autonomia da função editorial face às coerções econômicas e sociais. (Ouvry-Vial, 2007, p. 81). O que caracteriza o novo modelo cultural é que ele integra todas as expressões culturais e todas as mensagens funcionam de forma binária: presença/ausência no sistema de comunicação multimídia. O preço a pagar para se integrar é aderir à lógica do sistema, à sua linguagem e seus códigos.

\section{NOVAS MODALIDADES DE EDIÇÃO NA WEB}

Não resta dúvida de que o texto eletrônico reintroduz na escrita algo das línguas formais, ou seja, uma linguagem simbólica, capaz de representar as diversas formas de pensamento. "Se Condorcet vinculava estritamente o uso dessa língua universal à invenção e à di- fusão da imprensa, no mundo contemporâneo é em relação à textualidade eletrônica que se esboça um novo idioma formal imediatamente decifrável por todos" (Chartier, 2002, p. 16-17). Há uma transformação profunda na ordem do discurso com a institucionalização da textualidade eletrônica, pois a leitura diante da tela é descontínua e a percepção da obra como um todo é mais complexa. As novas tecnologias da informação introduzem novas técnicas de difusão da escrita, proporcionando uma revolução nas estruturas e na modalidade técnica da produção da escrita e nos suportes da escrita. Na concepção de Chartier (2002, p. 27),

[...] haverá duas formas de publicação: a que vai continuar a oferecer textos abertos, maleáveis, gratuitos, e a que resultará de um trabalho editorial que necessariamente fixará e fechará os textos publicados para o mercado. Talvez dois tipos de aparelhos vão corresponder a cada uma dessas formas: o computador tradicional para a primeira e o e-book, que não permite o transporte, a cópia ou a modificação dos textos, para a segunda.

A oposição entre, de um lado, o livro, a escrita, a leitura e, de outro, a tela e a imagem é substituída por uma nova situação que propõe um outro suporte para a cultura escrita e uma nova forma para o livro (Zilberman apud Chartier, 2002, p. 105-106). A coexistência entre o livro tradicional e o livro eletrônico nos faz refletir sobre as novas formas de construção dos discursos eruditos e as novas modalidades específicas de leituras que são permitidas pelo livro eletrônico. No que diz respeito ao livro eletrônico, não se trata, apenas, de uma substituição, uma vez que as formas têm um efeito sobre os sentidos. Assim, os livros eletrônicos organizam uma nova forma de relação entre as demonstrações e os critérios das provas (Graton, 1998). A lógica do texto não é mais, necessariamente, linear e dedutiva, mas aberta e relacional e oferece novas possibilidades argumentativas (Doglas, 1980). A revolução das modalidades de produção e de transmissão dos textos é, fundamentalmente, uma mudança epistemológica. As possibilidades do 
livro eletrônico levam o autor a organizar de forma diferente o que o livro distribui de forma linear e sequencial (Chartier, 2002, p. 108). A textualidade eletrônica coloca em questão a noção mesma do livro. "Daí a inquietação de nosso tempo diante da extinção dos critérios antigos que permitiam distinguir, classificar e hierarquizar os discursos. Não é pequeno o seu efeito sobre a própria definição do livro tal como o compreendemos [...]" (Chartier, 2002, p. 109-110). Critérios antigos, aos quais Chartier se refere, são os estabelecidos pelo editor.

Para pensar as novas relações entre o texto e a imagem, na perspectiva da incidência da noção de tela na produção e difusão do conteúdo ou da informação, é preciso medir bem a globalidade da percepção de um produto editorial feito de texto e imagem, mais precisamente de um texto concebido da mesma forma que uma imagem, tendo em vista os novos modos de difusão dos textos. Este produto da comunicação é tanto escrito quanto visual. O que deve ser introduzido é a relação entre texto e imagem, e o problema que emerge é a função do editor neste novo cenário.

Convém falar de uma nova forma de textualidade que institui uma interação entre a tela e a escrita. Trata-se de uma nova forma de produção, de interpretação e de estrutura ـ de significado. Isto implica, necessariamente, ڤิ a elaboração de novas estratégias de leitura da informação que levem em consideração a imagem e o texto (Lamizet, 1989, p. 68). É necessário, também, um novo tipo de relação com a memória e, a partir daí, pensar um novo tipo de uso dos sistemas de informação.

A presença da internet não dispensa a necessidade de se mobilizar o capital cultural no seu estado incorporado. Este capital é definido como um ter que se torna ser e, então, uma propriedade que se faz corpo ao tornarse parte integrante da pessoa (Bourdieu, 1998, p. 74-75). Portanto, as dificuldades cognitivas relativas ao processo de entrada no escrito não são alteradas e, de fato, exigem-se novas habilidades intelectuais. Convém alertar que o leitor-navegador também pode se perder nos arquipélagos textuais (Berring apud Chartier, 2002, p. 120-121). Os historiadores da leitura têm demonstrado que a leitura se tornou mais uma prática cultural silenciosa e solitária

Há uma distância crescente entre aqueles que utilizam as informações para atingir seus objetivos e os que são dominados pelo mercado de trabalho, as mídias, e são, também, reduzidos à dependência econômica e cultural. Para Manuel Castells (1998), a luta contra o determinismo tecnológico é indispensável. Mas é também necessário que a análise demonstre a interação das formas de produção e das relações sociais de produção. As economias se tornam mundializadas e essas transformações contribuem, também, para a acentuação do crescimento econômico desigual (Castells, 1998, p. 21-22). As inovações técnicas e suas aplicações sociais dependem de um conjunto complexo de interações e do sistema em vigor. É evidente que a capacidade ou não das sociedades para dominar as técnicas, em particular as que são estratégicas, tem um peso muito grande sobre o destino da sociedade.

No modo de desenvolvimento informacional, existe uma ligação estreita entre cultura e forças produtivas, entre espírito e matéria. Assim, novas formas de interação, de controle e de mudanças sociais são produzidas. As relações entre autor, leitor e editor se modificam profundamente. O período histórico em que estamos vivendo se caracteriza pela transformação da nossa cultura material e a emergência de um novo paradigma tecnológico organizado em torno das tecnologias da informação (Castells, 1998, p. 52-53). É preciso considerar a evolução da estrutura social do campo editorial e, assim sendo, a tipografia tem essa capacidade refinada para pensar de maneira conceitual. Na concepção de Postman (apud Castells, 1998, p. 377), ela tem uma forte apreciação da razão e da ordem, uma vez que a tipografia tem um grande poder de distanciamento.

Baseando-se em pesquisas empíricas, Manuel Castells (1998, p. 406) afirma que so- 
mente uma minoria é realmente ativa no sistema. A comunidade informatizada é a mídia do segmento mais instruído e a mais "aisé" da população dos países mais ricos. Isto significa que, nesta revolução tecnológica, a elite se beneficia de forma estrutural na nova sociedade. As universidades são os principais agentes de difusão das inovações tecnológicas no sentido de que, de geração em geração, os jovens universitários devem adotar novas maneiras de pensar, de agir e de se comunicar. Na concepção de Umberto Eco (apud Castells, 1998, p. 380), trata-se de assimilar novos códigos culturais. As novas mídias eletrônicas não se distanciam das culturas tradicionais. Na verdade, elas absorvem e modificam os modelos tradicionais. Todas as formas de comunicação estão baseadas na produção e no consumo de signos (Barthes, 1978; Jean Baudrillard, 1972).

O editor continua com sua função de selecionar e de filtrar o que deve ser publicado, conforme já se observou anteriormente. No entanto, a filtragem da informação é o problema essencial na Web. A cultura transmite a sua memória, mas, nem tudo que é transmitido ela filtra. Como bem diz Umberto Eco, toda história da cultura é a de colocar em prática determinados filtros. Os pesquisadores podem criticar a prática dos atores sociais que filtram, mas isto tem uma longa história. A Sociedade Internacional de Filosofia, por exemplo, faz uma monitoração de todos os sites de filosofia, contudo, esses problemas de filtragem na Web ainda não foram solucionados (Eco, 2003). Há uma distinção clara entre filtrar e censurar, no sentido de que a autoridade que filtra é um conselheiro que faz parte de um Conselho Editorial.

O objetivo da censura é controlar os textos impressos, os autores, os impressos e os livros. Em 1564, surgiu o índex dos livros proibidos e, somente em 1966, ele desapareceu. A figura do censor foi instituída pelo poder eclesiástico e, posteriormente, pelo poder político (Horellou-Lafarge; Segré, 2010, p. 5863). Em contrapartida, o editor é alguém que corrige em função de uma melhor estruturação do texto e não alguém que censura. E, também, porque editor e autor estão situados em uma rede de relações que pode ir até a identificação e é por essa razão que Henri Baillière apresenta a sua atividade editorial como uma simples colaboração (Fabiani, 1988, p. 104). Este trabalho de filtragem faz parte da educação e a censura consiste em impedir a circulação da informação. Um editor é um filtro e o leitor confia no editor porque ele pode publicar um péssimo romance, mas não abaixo de uma determinada estrutura que caracteriza o campo literário. O enorme problema é saber quem filtra o gosto literário na WEB. Se não há um filtro, a função de orientação crítica do editor desaparece. Tudo pode ser dito sobre a crítica, mas ela transmite um gosto cultural.

\section{CONCLUSÃO}

É necessário que haja uma função editorial na Web. Esta exigência se fundamenta em uma constatação que é a atestação da validade das informações na Web. Esta massa de informações incontroladas nos faz pensar em instâncias de regulação que permitam, não apenas filtrar, mas oferecer um modo de legitimação das fontes e os modos coerentes de ordenamento lógico dos discursos. A função editorial é definida como um poder crítico, e o problema principal não é saber se é necessário ou não, mas é discutir os modos de atualização do editor e os critérios de legitimação que se tornam necessários (Rieusset-Lemarié, 2001, p. 33).

A função do editor é importante visto que é através dele que a mensagem do autor se constitui e pode ser transmitida ao público através de um novo médium que é a Web. A importância desta mediação se deve ao fato de que ela inscreve a escrita de um sujeito na relação fundamental com o seu público. O autor fala por intermédio do editor. Hoje, a Web pode exercer este papel de intermediário, que dá o status de discurso público a um texto e a um tipo de documento. Neste sentido, a Web não é 
apenas um médium, mas uma rede de atores sociais ligados a um sistema. Mas, se esta difusão pública do World Wide Web recusa a mediação editorial, a tendência é os serveurs recusarem a responsabilidade jurídica dos conteúdos hospedados na página, alegando que eles são apenas prestadores de suporte técnico. Umberto Eco (2003) relata que começava a fazer uma pesquisa sobre um Saint-Graal e encontrou trinta sites. Como ele é bem informado sobre o objeto, não teve dificuldade para detectar que havia apenas um site de caráter filosoficamente correto, dois corretamente enciclopédicos e os demais eram loucos ocultistas delirantes. Assim, cada site da Web pode ter este papel de filtro editorial em relação a outras páginas da Web que orientam a leitura. O editor, na Web, tem esta função de orientação da leitura e deve cumprir esta prerrogativa social tão importante para a formação crítica do leitor. Isto não significa que um site que não tem o editor não tenha orientações de leitura implícitas. A análise destas questões diz respeito à enunciação editorial ou ao gesto editorial propriamente dito.

O problema essencial tem a ver com a explicitação da necessidade editorial na Web e do seu papel crítico, mas a grande dificuldade na internet é identificar as instâncias editorias que podem até estar no anonimato. É por isto Q que a explicitação da função editorial na interi net é determinante. Claro que se trata de uma capacidade e credibilidade para atestar o valor ซ్ das informações e isto exige instâncias editoriais reconhecidas. É preciso, então, desenvolver uma verdadeira competência crítica e científica. A exigência da internet é o desenvolvimento de uma função crítica colegiada, como $\dot{a}$ é o caso das editoras e dos periódicos. Trata-se

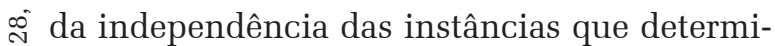

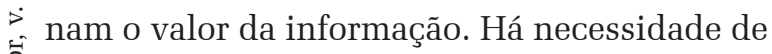
se pensar os modos de produção e de apresentação que fazem a diferença entre uma opinião e um texto científico (Rieusset-Lemarié , 2001, p. 38). Isto supõe uma mediação científica que não pode ser dissociada da função editorial tradicional. É preciso oferecer instrumentos para que os internautas possam perceber a validade de um texto, independentemente da presença ou ausência de etiquetas, a partir das quais as informações são transmitidas. É preciso, então, uma competência científica que permita estabelecer a diferença entre os falsos e os verdadeiros textos, por assim dizer. Este princípio é igualmente válido para os textos impressos. Tendo em vista que não podemos ser especialistas em tudo, cada vez mais necessitaremos de instâncias de legitimação científica.

O livro sempre foi uma mídia interativa. A força essencial das estruturas editoriais face à internet é o fundamento na mediação das obras. A especificidade da função editorial, diante da concorrência entre os autores, pode se fundar no fato de que os conteúdos editoriais não podem ser reduzidos aos conteúdos da informação. O que é estabelecido pelo editor não é apenas a informação. Além disso, ele pensa sobre a forma da obra e acrescenta, de fato, um novo significado ao manuscrito que se transforma em livro. Esta lógica cultural é específica da função editorial e pode ser, também, uma forma de buscar um equilíbrio econômico fundamentando-se no capital cultural desta competência específica. Esta lógica envolve todas as profissões relacionadas à indústria cultural, cujo equilíbrio instável se deve [a uma cultura] ao fato de ser fundada sobre certos valores culturais. Em síntese, as editoras são os principais instrumentos de construção das representações sociais.

Recebido para publicação em 03 de agosto de 2013 Aceito em 21 de novembro de 2014

\section{REFERÊNCIAS}

BARTHES, Roland. Le plaisir du texte. In: Oeuvres complètes. Paris: Seuil, v. 4. 2002.

BECKER, Howard. Outsiders. Études de la déviance. Paris: A. M. Métalié, 1985.

BOSCHETTI, Anna. Sartre et les “Temps Modernes": une entreprise intellectuelle. Paris: Les éditions de minuit, 1985.

BOURDIEU, Pierre. Escritos sobre a educação. Petrópolis: Vozes, 2008

Sur l'Etat. Cours au Collège de France 1989-1992. Paris: Seuil, 2012. 
Contre-feux2. Paris: Raison D’Agir Éditions, 2001

Champ intellectuel et projet créateur. Paris: Temps Modernes, novembre, p. 865-906, 1966.

La distinction: critique sociale du jugement. Paris: Les éditions de Minuit, 1979.

.Les règles de l'art: genèse et structure du champ littéraire. Paris: Le Seuil, 1992.

.Une révolution conservatrice dans l'édition. Actes de la recherche en sciences sociales. Paris, v. 126, n. 127 p. 3-28, mars, 1999.

BOUVERESSE, Jacques. Bourdieu, savant \& politique. Paris: Agone, 2003.

BURGUIÈRE, André. L'école des annales: une histoire intellectuel. Paris: cob, 2006.

CASSIRER, Ernest. Logique des sciences de la Culture. Paris: Cerf, 1991

La philosophie des formes symboliques. 1. Le langage. Paris: Les Editions de Minuit, 1972.

Substance et fonction. Éléments pour une théorie du concept. Paris: Les Editions de Minuit, 1977.

CASTELS Manuells. La société en réseaux. L’ère de l'information. Paris: Fayard, 1998.

CERTEAU, Michel de. Linvention du quotidien, v. 1: Arts de faire. Paris: UGE, coll. 10/18, 1980

CHARTIER, Roger. Culture écrite et Société. L'ordre des livres (XIV - XVIII siècle). Paris, Albin Michel, 1996.

História cultural, entre práticas e representações. Rio de Janeiro: Difel, 1990.

Cultura escrita, literatura e história. Conversas de Roger Chartier com Carlos Aguirre Anaya, Jesús Anaya Rosique, Daniel Goldin e Antonio Sabarit, Porto Alegre: Armed Editora, 2001.

A aventura do Livro, do leitor ao navegador, Conversações com Jean Lebrun. São Paulo: Fundação Editora da Unesp, 1998.

CLAYTON, Karen; BLUMBERG, Fran; AULD, Daniel P. The relationship between motivation, learning strategies and choice of environment whether traditional or including an online component. Britsh Journal of Educational Technology. London v. 41, n. 3, p. 349-364, 2010.

CONTAT, Michel. L'auteur et le manuscrit. Paris: Puf, 1991. DEBRAY, Régis. Introduction à la médiologie. Paris: Puf, 2000. DIRKX, Paul. Les obstacles à la recherche sur les stratégies éditoriales. Actes de la recherche en sciences sociales. Paris, v. 126, n. 127, p. 70-74, mars, 1999

DOUGLAS, Mary. Comment pensent les institutions: suivi de la connaissance de soi et il n'y a pas de don gratuit. Paris: Éditions la Découverte/Mauss, 1999.

ECO, Umberto. Auteurs et autorité, entretien avec Umberto Eco. In: Text-e. Lê texte à l'heure de l'internet, Paris: BPI Centre Pompibu, 2003. Disponível em: http://www.text-e. org/. Acesso em: 03 nov. 2010.

FABIANI, Jean-Louis. Les philosophes et la république. Paris: les éditions de minuit, 1988.

Sur quelques progrès récents de la sociologie des œuvres. Genèses. Paris, n. 11, p. 148-167, 1993.

FOUCAULT, Michel. A ordem do discurso. Aula inaugura no Collège de France, pronunciada em 2 de dezembro de 1970, São Paulo: Edições Loyola, 1996.

Archéologie du savoir. Paris: Gallimard, 1969.

O que é um autor? Portugal: Vega Passagens, 1992.
GÉRARD, Genette. Seuils. Paris: Seuil, 1987.

GRÉSILLON, Almuth. Éléments de critique générique. Lire manuscrits modernes. Paris: Puf, 1994.

HENRY, Anne C.; HANDLEY, Miriam. Ma(r)king the text. The presentation of meaning on the literary page. Ashgate: Edited Joe Bray, 2000.

HORELLOU-LAFARGE, Chantal; SEGRÉ, Monique. Sociologia da leitura. São Paulo, 2010.

JEANNERET, Yves; SOUCHIER, Emmanuel. L'énonciation éditoriale dans les écrits d'écran. Communication et langages. Paris, n. 145, p. 3-15, septembre, 1995. Disponível em: http:www.persee.fr. Acesso em: 03 nov. 2010.

LA REVUE FRANCAISE DE SOCIOLOGIE. Editorial, Qu'est-ce qui fonde la légitimité de l'évaluation scientifique? Revue française de sociologie. Paris, v. 50, n. 1, p. 1-2 septembre, 2009. Disponível em: http:www. persee.fr. Acesso em 09 nov. 2010.

MENGER, Pierre-Michel. Rationalité et incertitude de la vie d'artiste. L'année sociologique. Paris, v. 39, p. 115-151, septembre, 1989. Disponível em: <http:www.persee.fr>. Acesso em: 11 nov. 2010.

MOLLIER, Jean-Yves; SOREL, Patrícia. L'histoire de l'édition, du livre et de la lecture en France aux XIX et XX siècles. Approches bibliographiques. Actes de la recherche en sciences sociales. Paris, v. 126 n. 127, p. 39-59, mars, 1999.

MOLLIER, Jean-Yves. Les mutations de l'espace éditorial français du XVIII au XVIII au XX siècle. Actes de la recherche en sciences sociales. Paris, v. 126, n. 127, p. 2938, mars, 1999

L'argent et les lettres - histoire du capitalisme d'édition (1880-1920), Fayar, 1988

MEDEIROS, Nuno. O objeto dúctil. A emergência de uma sociologia histórica da edição. Revista Tempo Social da Usp, v. 22, n. 2, 2010.

NEIL, Fligstein. Rhétorique et réalités de la mondialisation, Actes de la recherche en sciences sociales. Paris, v. 119, n. 119, p. 36-47, septembre, 1997. Disponível em: http:www. persee.fr. Acesso em: 19 set. 2009.

OUVRY-VIAL, Brigitte. L'acte éditorial: vers une théorie du geste. Communication et langages. Paris: n. 154, p. 67-82, 2007. Disponível em: http:www.persee.fr. Acesso em: 03 nov. 2010 .

PICHOIS, Claude. Les cabinets de lecture à Paris Durant la première moitié du XIX siècle. In: Annales. Économie, Sociétés, Civilisations, 14 année, n. 3, 1959. Disponível em: www.persee.fr. Acesso em: 12 set. 2012.

RIEUSSET-LEMARIÉ, Isabelle. La médiation éditorial sur internet. Communication et langages. Paris: n. 130, p. 6782, 2001. Disponível em: http:www.persee.fr. Acesso em: 12 nov. 2010

SALAUN, Jean-Michel. Aspects économiques du modèle éditorial sur internet. Fonction éditorial et internet. Communication et langages. Paris: n. 130, p. 47-58, décembre, 2001. Disponível em: http:www.persee.fr. Acesso em: 04 nov. 2010).

SARTRE, Jean-Paul. Situations, II. Qu'est-ce que la littérature? Paris, Gallimard, 1948.

SIMONIN, Anne; FOUCHÉ, Pascal. Comment on a refusé certains de mes livres. Contribution à une histoire sociale du littéraire. Actes de la recherche en sciences sociales, Paris, v. 126, n. 127, p. 103-115, mars, 1999.

SORÁ, Gustavo. La maison et l'entreprise. José Olympio et l'évolution de l'édition brésilienne. Actes de la recherche en sciences sociales. Paris, v. 126, n. 127, p. 90-102, mars, 1999 


\section{SOCIAL GENESIS OF THE PUBLISHER AND THE NEW CONDITIONS OF BOOK PRODUCTION}

\section{Antonio Paulino de Sousa}

This article links the problem of traditional publishing with the new trends in the publishing sector and has the goal of establishing the social conditions for book production. The publisher is an intermediary between the author and his or her public. This dialectic relation between publisher and author is important to understand the book as a final product. The publisher has a critical role which is a determinant in the process of construction, circulation and attribution of new meanings. For this reason, we speak in terms of editorial writing, whose activity is being questioned by new reading strategies on the Web. The main problem is filtering on the Web. The editorial action remains essential for the legitimization and scientific validation of the discourses.

Keywords: Power. Publisher. Editorial field. Editorial enunciation, Web.

\section{LA GENÈSE SOCIALE DE L'ÉDITEUR ET LES NOUVELLES CONDITIONS DE PRODUCTION DU LIVRE}

\author{
Antonio Paulino de Sousa
}

Cet article fait le lien entre le problème de l'édition traditionnelle accompagnée des nouvelles tendances dans le champ de l'édition et cherche à établir les conditions sociales de production du livre. L'éditeur est un médiateur entre l'auteur et son public. Cette relation dialectique entre l'éditeur et l'auteur est importante pour bien comprendre ce produit final qui est le livre. Léditeur exerce une fonction critique déterminante dans le processus de construction, de circulation et d'attribution de nouveaux sens. C'est pour cette raison que l'on parle en termes d'écriture éditoriale dont l'activité est remise en question par les nouvelles stratégies de lecture sur la Toile (Web). Le problème essentiel est de savoir filtrer sur la Toile (Web). Le geste éditorial continue à être indispensable pour légitimer et valider le côté scientifique des discours.

Mots-clés: Pouvoir. Éditeur. Champ Editorial. Énonciation Éditorial, Toile (Web). atuando principalmente nos seguintes temas: Sociologia da educação, sociologia econômica (crise econômica) e o ensino da sociologia. Na Pós-Graduação leciona a disciplina Teoria das Ciências Sociais. Professor do programa de Pós-Graduação em Ciências Sociais (Mestrado e Doutorado) e do Programa de Pós-Graduação em Educação (Mestrado). Professeur/Chercheur-UFMA. Publicações recentes: Entre a pesquisa e o ensino na universidade. Revista discente perspectivas sociais, v. 01, p. 01-27, 2014; A sociologia cognitiva da economia. Revista Pós Ciências Sociais, v. 11, p. 225-230, 2014; O editor e as novas condições de produção do livro. Veredas. Revista da Associação Internacional de Lusitanistas, v. 21, p. $05-27,2014$. 